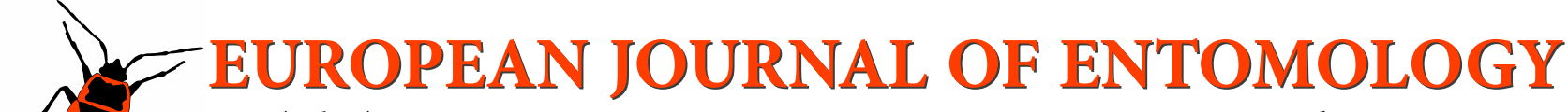 \\ ISSN (online): 1802-8829 \\ http://www.eje.cz \\ Eur. J. Entomol. 113: 462-468, 2016 \\ doi: 10.14411/eje.2016.060 \\ ORIGINAL ARTICLE
}

\section{Niche partitioning in tenebrionid species (Coleoptera: Tenebrionidae) inhabiting Mediterranean coastal dunes}

\author{
Simone FATtORINI ${ }^{1,2}$, Davide BeRgAMASCHI ${ }^{3}$, Cristina MANTONI $^{3}$, Alicia T.R. ACOSTA $^{3}$ and AndRea DI GIULIO ${ }^{3}$ \\ ${ }^{1}$ Department of Life, Health and Environmental Sciences, University of L'Aquila, Via Vetoio, Coppito, 67100, L'Aquila, Italy; \\ e-mail: simone.fattorini@univaq.it \\ ${ }^{2}$ CE3C - Centre for Ecology, Evolution and Environmental Changes / Azorean Biodiversity Group and University of the Azores, \\ Angra do Heroísmo, Terceira, Açores, Portugal \\ ${ }^{3}$ Department of Science, Roma Tre University, Viale G. Marconi 446, 00146, Rome, Italy; \\ e-mails: dav.bergamaschi@stud.uniroma3.it, cri.mantoni@stud.uniroma3.it, aliciateresarosario.acosta@uniroma3.it, \\ andrea.digiulio@uniroma3.it
}

Key words. Coleoptera, Tenebrionidae, dunes, geometric series, Mediterranean, niche overlap, niche preemption

Abstract. We analyzed the abundance, distribution and niche overlap of species (Pianka's $O_{j k}$ index) in tenebrionid beetle communities inhabiting different biotopes in Tyrrhenian and Adriatic sand dunes. The rank abundance distribution of the different species has the form of a geometric series in both communities as predicted by the niche preemption hypothesis for communities in harsh environments. Mean niche overlap values did not deviate significantly from null expectations, which indicates random interspecific interactions. These results, coupled with evidence of species habitat preferences, led us to conclude that the community organization of tenebrionid species inhabiting coastal dunes is determined more by habitat preferences than interspecific competition.

\section{INTRODUCTION}

One of the most controversial issues in insect ecology is the role of interspecific competition in determining community organization (Price et al., 2011; Schowalter, 2011). Research in this field is usually difficult because of the large number of species of insects in a community and the many factors determining community structure. For these reasons, important insights into the role of niche partitioning in insect community structure may come from studying simple systems.

Thanks to the small number of species of insects and low environmental diversity in coastal dunes, these environments are excellent model systems for studying insect community organization. Coastal sand dunes are widely recognized as harsh environments, with high levels of stress and disturbance, and characterized by high salinity, drought, high temperatures, high wind speeds, low vegetation cover and low productivity (Martínez \& Psuty, 2004; Feola et al., 2011), and hence host a low number of species of insects that are able to cope with these extreme conditions (McLachlan, 1991; Fattorini, 2008).

Among the beetles inhabiting Mediterranean sand dunes, tenebrionid beetles (Coleoptera: Tenebrionidae) are the most conspicuous component in terms of species richness, individual abundance and biomass (see Fattorini, 2008 for a review) and are, therefore, an ideal group for investigating how niche partitioning determines insect community structure in a simple ecosystem.

According to theoretical models and field evidence, the species abundance distribution in insect communities in harsh environments should take the form of a geometric series, which reflects community dynamics dominated by a single factor, for example food availability (Giller, 1984; Fattorini, 2005; He \& Tang, 2008). However, it is not clear if the niche partitioning revealed by a species abundance model reflects some form of competitive balance among species.

Direct evidence of competition can be obtained by manipulating competitors (Price et al., 2011), but this is extremely difficult in the field. However, an interesting alternative is to infer the possible presence of competition by testing whether observed patterns are statistically different from those expected based on chance. For example, assuming that competition should produce values of niche overlap lower than a random utilization of a certain resource, observed values can be compared with those obtained using null-models (Gotelli \& Graves, 1996).

In this paper, we investigate niche partitioning and overlap in tenebrionid communities in Mediterranean sand dunes in order to test: (1) if the species abundance distribu- 
tion in these communities follow a simple niche preemption model; (2) if there is any non-random pattern in niche overlap, and (3) if species abundance distribution is related to inter-specific competition or other factors.

\section{MATERIALS AND METHODS}

\section{Study site and insect sampling}

We studied community organization of tenebrionid beetles in two geographically separated dune systems in Central Italy: one on the Tyrrhenian coast (Montalto Marina, Latium region) and the other on the Adriatic coast (Campomarino, Molise region). Coastal zones are under severe human pressure, which may alter profoundly the structure of their insect communities (Fattorini, 2008). To minimize the possibility that the patterns are the result of anthropogenic influence we selected areas for study in relatively undisturbed coastal zones. As reported in previous ecological investigations, both of these sites have a relatively good conservation status (Acosta et al., 2009; Carboni et al., 2009).

At both sites, sampling was carried out along three transects separated by at least $100 \mathrm{~m}$ following a protocol similar to that of Fattorini et al. (2012). Along each transect, we identified three biotopes as defined by the European Commission $(1992,2007)$ (in parentheses EC codes): Embryonic shifting dunes (2110); shifting (white) dunes along the shoreline with Ammophila arenaria (2120); and Malcolmietalia dune grasslands (2230). These three biotopes were identified in the field based on the dominant and diagnostic plant species as indicated in the Habitat Directive Interpretation Manual (Santoro et al., 2012). In particular, the biotope corresponding to EC habitat 2110 is the closest to the seashore and is colonized by pioneer perennial plants such as Elymus farctus; the EC habitat 2120 occurs further inland and is the main dune ridge, which is mainly characterized by the presence of the dune-forming tussock grass, Ammophila arenaria; the EC habitat 2230 is even further inland and is in the transition zone between mobile and fixed dunes, and is colonized by many annual grasses (Acosta et al., 2005, 2009; Carboni et al., 2011). In each biotope, sampling was done using square plots of $2 \times 2 \mathrm{~m}$ and sieving a standard volume of sand. We first collected by hand all the beetles that were active on the ground in order to reduce the risk of their leaving the plot before being sampled. Hand sampling was done by systematically searching for beetles on the ground, under leaves and at the base of the plants. Then, we collected a fixed volume of 121 of sand. This volume was collected by dividing the $2 \times 2 \mathrm{~m}$ plot into four units of $1 \mathrm{~m}^{2}$ and collecting a sample of 31 of sand from the centre of each unit. Sand was collected by digging a surface area of about $400 \mathrm{~cm}^{2}$ to a depth of $2-3 \mathrm{~cm}$. To minimize the effect of the sampling on the abundance of animals, large sized tenebrionids (Pimelia Fabricius, 1775, Erodius Fabricius, 1775, and Tentyria Latreille, 1802) were placed in tubes, identified by an expert and released close to the plot where they were collected after all the plots at the same site were sampled. Small tenebrionids were identified in the laboratory. At each site adults were sampled on one day in spring and one in summer and the data were pooled for each biotope because of the small numbers of species and individuals collect along each transect and in each plot.

Most species occurred in all three biotopes (see co-occurrence analysis below), although with different abundances, and the species recorded in the plots of the same biotope were very similar. In contrast, the environmental characteristics of the three biotopes were different. Thus, the biotope was assumed to be the most appropriate scale for this study and all analysis were conducted at this scale.

\section{Data analysis}

Species-abundance distribution and spatial organization

We studied the overall species abundance distribution patterns at the two sites using a rank-abundance curve (May, 1975; Magurran, 1988; Hayek \& Buzas, 2010). Since the geometric series is the reference model for communities composed of a few species and with high dominance (Fattorini, 2005), we first used a $\chi^{2}$ test to determine if our data deviated significantly from the species abundance value predicted by this model. As our data did not deviate from the expected distribution, we used Ordinary Least Squares (OLS) regression described by Fattorini (2005) to model the rank-abundance curve. This approach is based on the fact that, if species are ranked from the most to the least abundant, and abundances are logarithmically transformed, a geometrical series exactly follows a strength line, which can be fitted using an OLS regression. The coefficient of determination $R^{2}$ can then be used as a goodness-of-fit measure. The geometric series is the mathematical model used to express the "niche preemption" hypothesis, in which the sizes of the niche hypervolumes (measured by species relative abundances) are sequentially preempted by the most abundant to the least abundant species. The first species in the sequence occupies a fraction $k$ of the resource hypervolume, the second species a fraction $k$ of hypervolume not occupied by the first, and so on. The niche preemption parameter $k$ was calculated following He \& Tang (2008).

We compared the slopes of the two regression lines using ANCOVA. We used the same approach to compare rank-abundance curves for the three biotopes at the Tyrrhenian site and those of the embryonic shifting dune biotope at the two sites. We refrained from other comparisons because of the small number of species occurring in the other biotopes at the Adriatic site. Calculations were done using PAST 3 (Hammer et al., 2001).

To determine if there is an association between species and habitat (i.e. if different proportions of the species occurred in different biotopes) we applied a $\chi^{2}$ test to a species $\times$ biotope contingency table. To reveal the main spatial organization, variation in the species distributions at the two sites and in the different biotopes were analyzed using Detrended Correspondence Analysis (DCA) with CANOCO software (ver. 4.5A) (Ter Braak \& Šmilauer, 2002).

\section{Niche overlap and species segregation}

To express niche overlap between species pairs, we calculated the Pianka (1973) index of niche overlap using EcoSimR 1.00 (Gotelli \& Ellison, 2013):

$$
O_{j k}=O_{k j}=\frac{\sum_{i}^{n} p_{i j} p_{i k}}{\sqrt{\sum_{i}^{n} p_{i j}^{2} \sum_{i}^{n} p_{i k}^{2}}}
$$

where $O_{j k}$ is Pianka's index of niche overlap between species $j$ and $k, p_{i j}$ is the proportion of the $i$ th resource used by species $j, p_{i k}$ is the proportion of the $i$ th resource used by species $k$, and $n$ is the total number of resources.

This index is a modification of the asymmetric index proposed by MacArthur \& Levins (1967) for estimating competition coefficients from field data on resource utilization. It is an analogue of a correlation coefficient and ranges from zero (complete dissimilarity in resource utilization between two species) to one (complete identity in resource utilization). Pianka's symmetric measure is more convenient than the original MacArthur and Levins' asymmetric form (May, 1974). Moreover, there is a general agreement that overlap measures cannot be used as true competition coefficients (Hurlbert, 1978; Abrams, 1980; Holt, 1987) and it is 
suggested that there is an inverse relationship between competition and niche overlap (Pianka, 1976, 1978). For these reasons, MacArthur and Levins' original measure is now largely replaced by Pianka's symmetrical version. Indeed, niche overlap may reflect intense competition for shared resources or, alternatively, a surplus of resources and the absence of competition (Glasser \& Price, 1988). Thus, we do not consider values obtained from Pianka's index as "competition coefficients," but merely as measures of niche overlap (see Colwell \& Futuyma, 1971; Pianka, 1974 for the distinction between overlap and competition).

To assess if the mean values of niche overlap recorded at each site were different from those expected by chance, we compared the observed values with the expected averages obtained from 10,000 simulated null-assemblages (pseudo-communities). This number of permutations is enough to avoid algorithm biases in calculations (Lehsten \& Harmand, 2006).

Null-assemblages were simulated using Monte Carlo randomization algorithms that assign resource use values (in our case, number of individuals from different biotopes) to each species. The choice of an appropriate model to construct null-assemblages is a critical issue. Lawlor (1980) developed four randomization algorithms that differ in whether utilizations are reshuffled or replaced by a random number and whether the zeros in the matrix are retained or not. These algorithms are referred to as RA1, RA2, RA3 and RA4. Both retaining/relaxing niche breadths and retaining/reshuffling zeros have implications for the structure of the null community and affect the power of the test (Gotelli \& Graves, 1996). Theoretical and empirical analyses of these algorithms (Winemiller \& Pianka, 1990; Kobayashi, 1991) led to the conclusion that Lawlor's (1980) RA3 is probably the best algorithm for use in resource overlap null models. This algorithm tests for community structure by retaining niche breadth (i.e. the amount of specialization) for each species (simulated specialization equal to the observed value), but reshuffles zero states (i.e. by randomly varying the particular resources that were used), thus destroying the guild structure manifested by the zero structure of the resource utilization matrix.

However, RA3 tends to overestimate niche overlap if the equiprobability assumption is not met, because more abundant resources will be used by all species even if niche segregation occurs. Thus, we also used, for comparative purposes, the RA2 algorithm, which tests for structure in the generalist-specialist nature of the resource utilization matrix by conserving guild structure (zero states are retained, thus preventing species that did not use a certain resource in the field from doing so in simulations), but relaxes niche breadth (thus assuming a random equiprobable specialization) (Gotelli \& Graves, 1996). Structure was assumed when $P_{\text {obs }<\exp }=0.05$ or less (Gotelli \& Graves, 1996). In all cases, equiprobable resource use was a-priori assumed in the analyses, because resource availability data were not available. To investigate between-site differences in niche overlap, we compared mean overlap values using Student's t-test.

We also calculated species segregation using Stone and Robert's (1990) C-score. The C-score for a species pair $j k$ is calculated as:

$C_{j k}=\left(R_{j}-S S\right)\left(R_{k}-S S\right)$

where $R_{j}$ is the row total for species $j, R_{k}$ is the row total for species $k$, and $S S$ is the number of samples that contain both $j$ and $k$. Thus, for any particular species pair, the C-score is a numerical index that ranges from a minimum of 0 (maximally aggregated) to a maximum of $\mathrm{R}_{j} \mathrm{R}_{k}$ (maximally segregated with no shared samples). The matrix-wide C-score is an average of all the pairwise values of $\mathrm{C}$-score for different species, so it reflects both positively and negatively associated species pairs. To establish
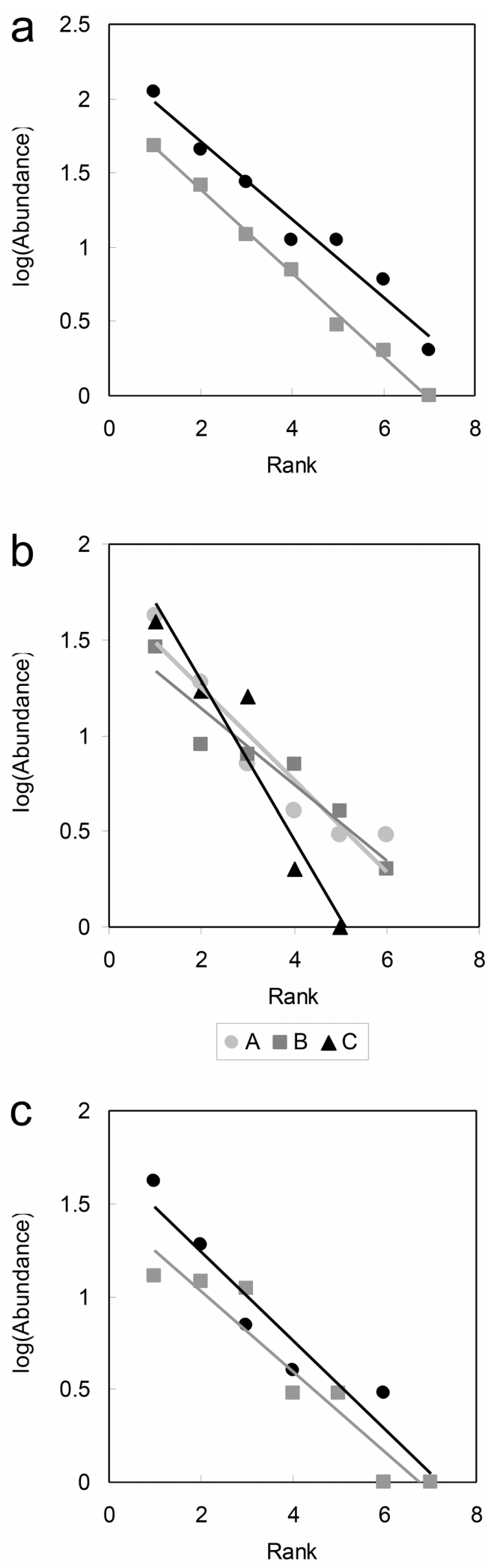

Fig. 1. Rank-abundance plot of the tenebrionid beetles inhabiting Tyrrhenian and Adriatic beach-dune systems. Species are ranked from the most to the least abundant ( $x$-axis). Species abundances are log-transformed ( $y$-axis). Data were fitted using ordinary least squares regressions. Figure 1a refers to overal rank-abundance curves for the Tyrrhenian (in black) and Adriatic (in grey) sites. Figure $1 \mathrm{~b}$ presents rank-abundance curves for the three biotopes $(A$, $B$ and $C$; see Table 1) at the Tyrrhenian site. Figure 1c compares rank-abundance curves for biotope $A$ at the Tyrrhenian (in black) and Adriatic (in grey) sites. 


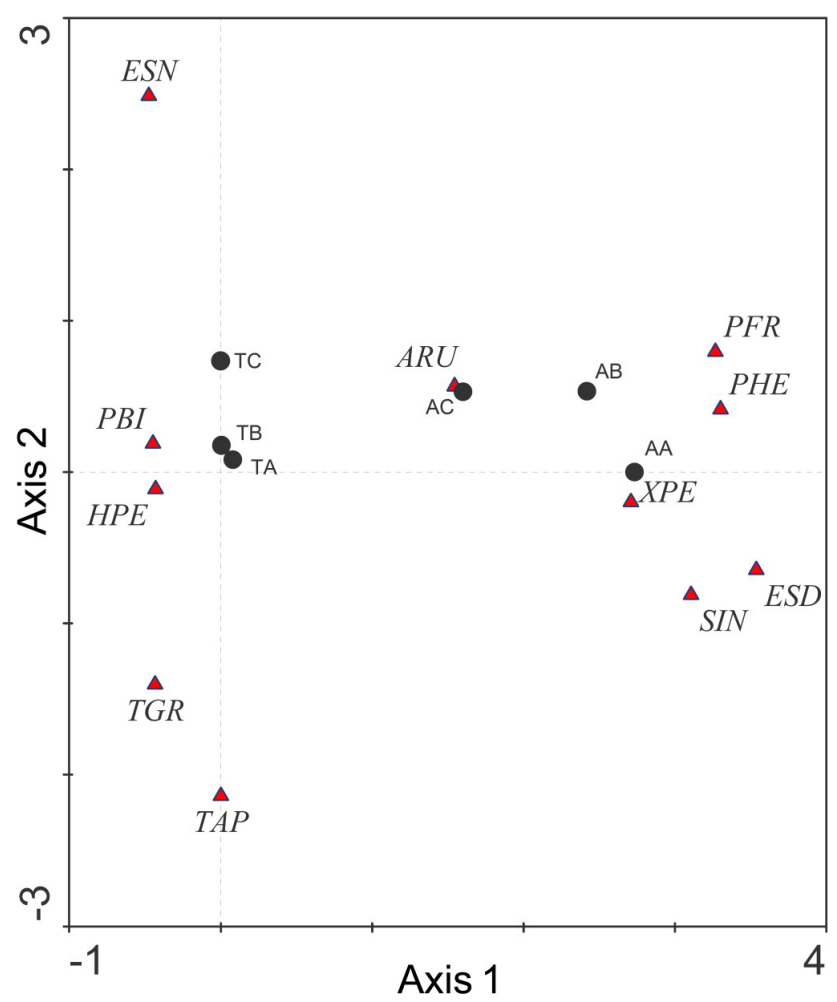

Fig. 2. Ordination diagram based on the first two axes of a Detrended Correspondence Analysis. Triangles indicate the species and dots the biotopes. Species acronyms are as follows: ARU - Ammobius rufus; ESD - Erodius siculus dalmatinus; ESN - Erodius siculus neapolitanus; HPE - Halammobia pellucida; PBI - Pimelia bipunctata; PFR - Pachychila frioli; PHE - Pseudoseriscius helvolus; SIN - Stenosis intermedia; TAP - Trachyscelis aphodioides; TGR - Tentyria grossa; XPE - Xanthomus pellucidus. Site acronyms are as follows: AA - Adriatic embryonic shifting dunes $A B$ - Adriatic shifting dunes along the shoreline with Ammophila arenaria; AC - Adriatic Malcolmietalia dune grassland; TA - Tyrrhenian Embryonic shifting dunes; TB - Tyrrhenian shifting dunes along the shoreline with Ammophila arenaria; TC - Tyrrhenian Malcolmietalia dune grassland.

whether the matrix had an average C-score significantly different from what can be expected from a null-model, we compared the observed values with the expected averages obtained from 10,000 simulated null-assemblages using the FF algorithm, which preserved row and column totals (Ulrich \& Gotelli, 2007). For comparative purposes, we also used the fixed row-equiprobable column (FE) algorithm, which preserved row totals (species occurrences) but treated columns (sampled biotopes) as equally probable, thus allowing species number per biotope to vary in the null assemblages.

High average $\mathrm{C}$-scores indicate a lower randomness, i.e. a greater likelihood that the distribution of one species has been directly affected by the presence of other species. If a community were structured by competition, we would expect the C-score to be large relative to a randomly assembled community. While niche overlap analysis uses a data matrix with species- and sitespecific observed frequencies, the C-score searches for a nonrandom structure in the species assemblages by using a presence/ absence data matrix (Gotelli \& Graves, 1996).

\section{RESULTS}

At both sites, the overall species abundance distribution did not deviate significantly from that expected according to the geometric series model, with $k=0.487$ for the Tyrrhenian site $\left(\chi^{2}=6.159, \mathrm{df}=6, P=0.291\right)$ and $k=0.475$ for the Adriatic site $\left(\chi^{2}=0.250, \mathrm{df}=6, P=0.970\right)$.

The equations of the OLS regression lines were: $\log ($ Abundance $)=-0.263 \times \operatorname{Rank}+2.236$, with $R^{2}=0.967$ for the Tyrrhenian site, and $\log ($ Abundance $)=-0.281 \times$ Rank +1.953 , with $R^{2}=0.996$ for the Adriatic site (Fig. 1a). The slopes of the two regression lines were not significantly different (ANCOVA for the homogeneity of slopes: $F=0.630, P=0.446)$.

For the Tyrrhenian site, the equations of the regression lines were: $\log ($ Abundance $)=-0.239 \times \operatorname{Rank}+1.722$, with $R^{2}=0.900$ for embryonic shifting dunes, $\log$ (Abundance) $=-0.198 \times$ Rank +1.537 , with $R^{2}=0.911$ for shifting dunes with Ammophila arenaria, and $\log ($ Abundance $)=$ $-0.411 \times$ Rank +2.099 , with $R^{2}=0.918$ for Malcolmietalia dune grassland (Fig. 1b). The slopes of the three regression lines were significantly different (ANCOVA for the homogeneity of slopes: $F=5.058, P=0.028$ ) because of the high slope of the Malcolmietalia dune grassland regression line. The other two biotopes has similar slopes $(F=0.679$, $P=0.434)$. Regression lines for embryonic shifting dunes at the two sites had similar slopes $(F=0.213, P=0.656)$ (Fig. 1c).

Overall mean niche overlap at the Tyrrhenian site was $64 \%$ and $56 \%$ at the Adriatic site (Table 2). At both sites, the observed mean values were not significantly lower than the respective simulated assemblages, regardless of the randomization algorithm used (Table 2).

Overall mean niche overlap values were not significantly different at the two sites $(t=1.087, \mathrm{df}=40, P=0.284)$.

An analysis of co-occurrences using the FF algorithm revealed that at both sites species distribution among biotopes did not deviate significantly from a random pattern, with observed C-scores even lower than those expected [observed C-score $=0.143$, mean of simulated C-score $=$

Table 1. Abundance of tenebrionid species recorded in three biotopes along transects in Tyrrhenian and Adriatic dunes. A - embryonic shifting dunes; $\mathrm{B}$ - shifting dunes along the shoreline with Ammophila arenaria; C - Malcolmietalia dune grasslands.

\begin{tabular}{lrrr}
\hline & \multicolumn{3}{c}{ Biotope } \\
\cline { 2 - 4 } & $\mathrm{A}$ & $\mathrm{B}$ & $\mathrm{C}$ \\
\hline Tyrrhenian dunes & & & \\
Ammobius rufus (Lucas, 1846) & 9 & 17 \\
Erodius siculus neapolitanus Solier, 1834 & 3 & 8 & 16 \\
Halammobia pellucida (Herbst, 1799) & 4 & 0 & 2 \\
Pimelia bipunctata Fabricius, 1781 & 42 & 29 & 39 \\
Stenosis intermedia (Solier, 1838) & 0 & 2 & 0 \\
Tentyria grossa Besser, 1832 & 3 & 7 & 1 \\
Trachyscelis aphodioides Latreille, 1809 & 7 & 4 & 0 \\
Adriatic dunes & & & \\
Ammobius rufus (Lucas, 1846) & 11 & 17 & 20 \\
Erodius siculus dalmatinus Kraatz, 1865 & 3 & 0 & 0 \\
Pachychila frioli Solier, 1835 & 3 & 4 & 0 \\
Pseudoseriscius helvolus (Küster, 1852) & 13 & 13 & 0 \\
Stenosis intermedia (Solier, 1838) & 12 & 0 & 0 \\
Trachyscelis aphodioides Latreille, 1809 & 1 & 0 & 0 \\
Xanthomus pellucidus Mulsant et Rey, 1856 & 1 & 0 & 1 \\
\hline
\end{tabular}


Table 2. Pianka niche overlap indices recorded for tenebrionid communities in Tyrrhenian and Adriatic sand dunes. RA2 (relaxed niche breadth) and RA3 (retained niche breadth) are the two algorithms used to construct null-assemblages.

\begin{tabular}{|c|c|c|c|c|c|}
\hline & \multirow{2}{*}{$\begin{array}{l}\text { Observed } \\
\text { overlap }\end{array}$} & \multicolumn{2}{|c|}{ RA2 } & \multicolumn{2}{|c|}{ RA3 } \\
\hline & & $\begin{array}{c}\text { Expected overlap } \\
\pm \text { variance }\end{array}$ & $P$ (observed $\leq$ expected) & $\begin{array}{l}\text { Expected overlap } \\
\pm \text { variance }\end{array}$ & $P$ (observed $\leq$ expected) \\
\hline Tyrrhenian dunes & 0.642 & $0.631 \pm 0.003$ & 0.561 & $0.679 \pm 0.002$ & 0.224 \\
\hline Adriatic dunes & 0.562 & $0.587 \pm 0.008$ & 0.404 & $0.521 \pm 0.003$ & 0.797 \\
\hline
\end{tabular}

$0.155, P$ (observed $<$ expected $)=0.755$, for the Tyrrhenian site, and observed C-score $=0.095$, mean of simulated $\mathrm{C}$-score $=0.095, P($ observed $<$ expected $)=1.000$ for the Adriatic site]. Use of the FE algorithm gave similar results [mean simulated C-score $=0.093, P$ (observed $<$ expected) $=0.905$ for the Tyrrhenian site, and mean simulated $\mathrm{C}$-score $=0.474, P($ observed $<$ expected $)=0.061$ for the Adriatic site].

The pairwise $\mathrm{C}$-scores were only greater than zero for Halammobia pellucida (Herbst, 1799), Stenosis intermedia (Solier, 1838) $(\mathrm{C}=2)$ and Trachyscelis aphodioides Latreille, $1809(\mathrm{C}=1)$ at the Tyrrhenian site, and for Xanthomus pellucidus Mulsant et Rey, 1856, Pachychila frioli Solier, 1835 and Pseudoseriscius helvolus (Küster, 1852) $(\mathrm{C}=1)$ at the Adriatic site.

We found an association between species abundance and biotopes in both the Tyrrhenian $\left(\chi^{2}=46.071\right.$, df $=12, P$ $=0.001)$ and Adriatic $\left(\chi^{2}=32.932, \mathrm{df}=12, P<0.0001\right)$ communities, which indicates that species have different habitat preferences.

The lengths (in SD units) of the DCA gradients (Fig. 2) were as follows: $2.734,0.735,0.603$ and 1.149 . This indicates that the first gradient is very important and thus the variation in the spatial distribution of species in tenebrionid assemblages is largely explained by the first axis. Axis 1 explained $59.3 \%$ and Axis $27.1 \%$ of the variance. Axis 3 explained only $0.8 \%$ of the variance. The total explained variance was 67.4 and the sum of all egeievalues was 1.107 .

\section{DISCUSSION}

Tenebrionids are the most abundant beetles in Italian beach-dune systems (Fattorini, 2008). The tenebrionid beetles living in Mediterranean coastal dunes include both omnivorous-opportunistic, large species, with a low population density (such as Pimelia bipunctata Fabricius, 1781, Tentyria grossa Besser, 1832, Erodius siculus Solier, 1834) and detritivorous, medium or small species with a high population density [such as Ammobius rufus (Lucas, 1846)]. Obviously, not all small species are abundant. The small $A$. rufus is always very abundant, but $T$. aphodioides, another very small species, is a less abundant species (Fattorini, 2008). This is also the case for the communities investigated in the present study, in which $A$. rufus accounted for $21 \%$ of individuals at the Tyrrhenian site and $53 \%$ of those at the Adriatic site, respectively, whereas T. aphodioides accounted for $5 \%$ at the Tyrrhenian site and $1 \%$ at the Adriatic site, respectively. The low frequency of T. aphodioides, a burrowing but winged species, could be related to the windy nature of coastal environments. At both of the sites studied, we recorded a total of 7 tenebrionid species, a richness value similar to that recorded at other well preserved coastal sites in Italy (usually less than 10 species: Fattorini, 2008).

Tenebrionid communities in Mediterranean sand dunes are also characterized by a very simple structure, with a high dominance of certain species (Fattorini \& Carpaneto, 2001; Carpaneto \& Fattorini, 2001, 2003; Fattorini et al., 2012). Simple communities in early stages of successions, as well as those that are subject to strong pressures or are energetically poor, where $r$-selected species are favoured, are known to have species abundance distributions that follow the geometric series (Whittaker, 1965, 1972; Bazzaz, 1975; Gray, 1981; Giller, 1984; Nummelin, 1998; Keeley \& Fotheringham, 2003). As already found for tenebrionid assemblages in other sand dune systems (see Fattorini, 2008), the geometric series provided an excellent fit for both of the communities studied. The slopes of the two regression lines were also similar, which indicates that the two communities have an analogous pattern of species abundance distribution and the resource hyperspace is divided in a similar way in the two communities. This is confirmed by a comparison of the embryonic shifting dune biotope, for which there are similar slopes for the two sites. In terms of the parameter $k$, which indicates the sequential, constant proportion of the total number of individuals in a community, it was about 0.5 for both systems, which indicates a rather sharp decline in the species niche hypervolumes, which is expected in communities where resources are divided according to the preemption theory. This decline was particularly strong in the Malcolmietalia dune grassland biotope at the Tyrrhenian site, because of the strong dominance of $P$. bipunctata, a very large, opportunistic beetle that also occurs in relatively highly anthropised areas.

The two tenebrionid communities studied not only had similar species abundance distribution patterns, but also similar values of mean niche overlap. This indicates that the two communities respond in a similar way to analogous constraints along the sea-inland environmental gradient, although located in very different geographical regions.

A community structure with $P$ (observed $<$ expected $)=$ 0.05 or less is considered compatible with the occurrence of interspecific competition, whereas significant aggregation of species, e.g. thanks to an unlimited resource, is indicated when $P$ (observed $>$ expected $)=0.05$ or less $($ Gotelli \& Graves, 1996). Based on this the two tenebrionid communities are not structured by interspecific competition because their mean niche overlap values were not sig- 
nificantly different from those obtained assuming a random partitioning of resources.

The role of competition in structuring tenebrionid communities is poorly explored. For example, different daily temporal strategies are evoked as a possible factor reducing competition between the dune species $T$. grossa and $P$. bipunctata (Fallaci et al., 1994) and a possible spatial separation has been suggested for two closely related syntopic congeneric species (see Fattorini, 2008). Of course, these forms of separation cannot operate in the species studied, because they were sampled simultaneously and no congeneric species were found at the same site. A study of a tenebrionid community in coastal sand dunes at El Saladar (Alicante, SE Spain) revealed substantial ecological overlap and no clear morphological evidence for interspecific competition, which indicates that competitive exclusion did not affect the species studied (Cantarino \& Roman, 1991).

Our study was limited to one taxonomic assemblage, thus we cannot speculate about other species in other taxa that might compete for resources with tenebrionids. During sampling, however, we observed very few other macro-arthropods, such as spiders, larvae of myrmeleontids, anthicid beetles, curculionid beetles, scarab beetles of the tribe Psammodini and hemipterans. Spiders and larvae of myrmeleontids are predators, whereas curculionid beetles and hemipterans are phytophagous. Psammodini beetles and anthicid beetles are detritivores. However, Psammodini beetles were very rarely found and anthicid beetles are much smaller than tenebrionids, so competition, if it occurs, is likely to be very low.

Although a non-random structure of species assemblages does not necessarily imply competitive interactions, communities regulated by intense competition should exhibit non-random structures (Gotelli \& Graves, 1996; Gotelli, 2000; Gotelli \& McGill, 2006). This study revealed that mean niche overlap between species of tenebrionids in coastal dunes were not significantly different from that expected by chance, which indicates that these communities are not regulated by competition. This is also supported by co-occurrence analysis, which indicates that there is no species segregation. The most obvious factor that is likely to influence the abundance of tenebrionid species in sand dunes is food availability. All the tenebrionid species studied are generalist detritivores that may feed on a variety of decaying matter with no particular specialization (Fattorini, 2008). This lack of trophic specialization is consistent with the high niche overlap recorded between species and lack of segregation.

On the other hand, as already recorded in previous studies (Fattorini, 2008; Fattorini et al., 2012), we also found that the abundance of tenebrionid species varied significantly in the three biotopes studied [i.e. embryonic shifting dunes (EC habitat 2110), shifting dunes with Ammophila arenaria (EC habitat 2120) and Malcolmietalia dune grassland (EC habitat 2230)], which indicates that different species have different habitat preference. Because most species at the two sites sampled occurred in all three biotopes, spe- cies-biotope associations are expected to be weak. Thus, it is not surprising that the distribution of the species in the correspondence analysis plot is scattered. However, it is interesting to note that $A$. rufus is placed very close to the Malcolmietalia biotope at the Adriatic site (where it is the most abundant species) and P. bipunctata and H. pellucida to embryonic shifting dunes and Ammophila biotopes at the Tyrrhenian site.

The two sites were clearly separated by the correspondence analysis, based on their different species compositions, but the three biotopes, at each site, clustered in a similar way in the space defined by the two main axes, which further indicates that the two communities respond in a similar way to analogous constraints, although located in very different geographical regions. Thus, the comparative evidence of (1) the dominance of the most common species, highlighted by the geometric series distribution, (2) the absence of resource partitioning based on niche overlap and species segregation null models and (3) the differences in habitat preferences of the species revealed by the species abundance distributions, led to the conclusion that community organization in tenebrionid species inhabiting coastal dunes is determined by habitat preferences rather than by interspecific competition.

ACKNOWLEDGEMENTS. We would like to thank F. Bellotti, C. Berardi, F. Bernardini, L. Germani, S. Manzini, L. Murgia, G. Poeta, F. Romiti, G.L. Scardaci, M. Tini and F. Velletrani for their help with the fieldwork. We are grateful to two anonymous referees for their useful comments on a previous version of this paper.

\section{REFERENCES}

ABRAMS P. 1980: Some comments on measuring niche overlap. Ecology 61: 44-49.

Acosta A.T.R., Carranza M.L. \& Izzi C.F. 2005: Combining land cover mapping of coastal dunes with vegetation analysis. - Appl. Veg. Sci. 8: 133-138.

Acosta A.T.R., Carranza M.L. \& Izzi C.F. 2009: Are there habitats that contribute best to plant species diversity in coastal dunes? - Biodivers. Conserv. 18: 1087-1098.

BAzZAZ F.A. 1975: Plant species diversity in old-field successional ecosystems in southern Illinois. - Ecology 56: 485-488.

CAntarino C.M. \& Roman E.S. 1991: Morphological indices and resource portioning in a guild of Coleoptera: Tenebrionidae at the coastal sand-dunes of Alicante (SE Spain). In Zunino M., Bellés X. \& Blas M. (eds): Advances in Coleopterology. European Association of Coleopterology, Barcelona, pp. 211-222.

Carboni M., Carranza M.L. \& Acosta A.T.R. 2009: Assessing conservation status on coastal dunes: A multiscale approach. - Landsc. Urban Plan. 91: 17-25.

Carboni M., Santoro R. \& Acosta A.T.R. 2011: Dealing with scarce data to understand how environmental gradients and propagule pressure shape fine-scale alien distribution patterns on coastal dunes. - J. Veg. Sci. 22: 751-765.

Carpaneto G.M. \& FatTorini S. 2001: Spatial and seasonal organisation of a darkling beetle (Coleoptera: Tenebrionidae) community inhabiting a Mediterranean coastal dune system. - Ital. J. Zool. 68: 207-214.

Carpaneto G.M. \& Fattorini S. 2003: Seasonal occurrence and habitat distribution of tenebrionid beetles inhabiting a Mediterranean coastal dune (Circeo National Park, Italy). - Rev. Ecol. / Terre Vie 58: 293-306. 
Colwell R.K. \& Futuyma D.J. 1971: On the measurement of niche breadth and overlap. - Ecology 52: 567-576.

European Comission 1992: Council Directive 92/43/EEC of 21 May 1992 on the conservation of natural habitats and of wild fauna and flora. Official Journal L 206, 22/07/1992, 7-50 and its amending acts.

EUROPEAN COMMISSION 2007: Interpretation manual of European Union Habitats, Eur 27. European Commission, DG Environment, Strasbourg, 2007, 142 pp. URL: http://ec.europa.eu/environment/nature/legislation/habitatsdirective/docs/2007 07 im.pdf.

Fallaci M., Colombini I. \& Chelazzi L. 1994: An analysis of the Coleoptera living along a Tyrrhenian beach-dune system: abundance, zonation and ecological indices. - Vie Milieu 44: 243-256.

FATTORINI S. 2005: A simple method to fit geometric series and broken stick models in community ecology and island biogeography. - Acta Oecol. 28: 199-205.

FATTORINI S. 2008: Ecology and conservation of tenebrionid beetles in Mediterranean coastal areas. In Fattorini S. (ed.): Insect Ecology and Conservation, Research Signpost. Trivandrum, Kerala, pp. 165-297.

Fattorini S. \& Carpaneto G.M. 2001: Tenebrionid density in Mediotyrrhenian coastal dunes: habitat and temporal variations (Coleoptera, Tenebrionidae). - Frag. Entomol. 33: 97-118.

Fattorini S., Santoro R., Maurizi E., Acosta A.T.R. \& Di Giulio A. 2012: Environmental tuning of an insect ensemble: the tenebrionid beetles inhabiting a Mediterranean coastal dune zonation. - C. R. Biol. 335: 708-711.

Feola S., Carranza M.L., Schaminée J.H.J., Janssen J.A.M. \& Acosta A.T.R. 2011: EU habitats of interest: an insight into Atlantic and Mediterranean beach and foredunes. - Biodivers. Conserv. 20: 1457-1468.

GILLER P.S. 1984: Community Structure and the Niche. Chapman and Hall, London, $176 \mathrm{pp}$.

Glasser J.W. \& Price H.J. 1988: Evaluating expectations deduced from explicit hypotheses about mechanisms of competition. - Ecology 51: 57-70.

Gotelli N.J. 2000: Null model analysis of species co-occurrence patterns. - Ecology 81: 2606-2621.

Gotelli N.J. \& Ellison A.M. 2013: EcoSimR 1.00. URL: http:/ www.uvm.edu/ ngotelli/EcoSim/EcoSim.html

Gotelli N.J. \& Graves G.R. 1996: Null Models in Ecology. Smithsonian Institution Press, Washington, $388 \mathrm{pp}$.

Gotelli N.J. \& McGill B.J. 2006: Null versus neutral models: what's the difference? - Ecography 29: 793-800.

Gray J.S. 1981: The Ecology of Marine Sediments. Cambridge University Press, Cambridge, 185 pp.

Hammer Ø., Harper D.A.T. \& Ryan P.D. 2001: PAST, Palaeontological statistics software package for education and data analysis, ver. 1.89. - Palaeontol. Electron. 4: 1-9.

HAYEK L.C. \& BuZAS M.A. 2010: Surveying Natural Populations: Quantitative Tools for Assessing Biodiversity. Columbia University Press, New York, 616 pp.

He F. \& TANG D.L. 2008: Estimating the niche preemption of the geometric series. - Acta Oecol. 33: 105-107.

Holt R.D. 1987: On the relation between niche overlap and competition: the effect of incommensurable niche dimensions. Oikos 48: 110-114.

HURLBERT S. 1978: The measurement of niche overlap and some relatives. - Ecology 59: 67-77.
Keeley J.E. \& Fotheringham C.J. 2003: Species-area relationships in Mediterranean climate plant communities. - J. Biogeogr. 30: 1629-1657.

KoBAYASHI S. 1991: Interspecific relations in forest floor coleopteron assemblages: niche overlap and guild structure. - Res. Popul. Ecol. 33: 345-360.

LAWLOR L.R. 1980: Structure and stability in natural and randomly constructed competitive communities. - Am. Nat. 116: 394-408.

Lehsten V. \& HaRmand P. 2006: Null models or species co-occurrence patterns: assessing bias and minimum iteration number for the sequential swap. - Ecography 29: 786-792.

MacArthur R. \& Levins R. 1967: The limiting similarity, convergence, and divergence of coexisting species. - Am. Nat. 101: 377-385.

MagurRan A.E. 1988: Ecological Diversity and its Measurement. Princeton University Press, Princeton, 179 pp.

Martínez M.L. \& Psuty N.P. 2004: Coastal Dunes. Ecology and conservation. Springer, Berlin, $388 \mathrm{pp}$.

MaY R.M. 1974: On the theory of niche overlap. — Theor. Popul. Biol. 5: 297-332.

MaY R.M. 1975: Patterns of species abundance and diversity. In Cody M.L. \& Diamond M.J. (eds): Ecology and Evolution of Communities. Harvard University Press, Cambridge, pp. 81120.

McLachlan A. 1991: Ecology of coastal dunes. - J. Arid Environ. 21: 229-243.

NumMELIN M. 1998: Log-normal distribution of species abundances is not a universal indicator of rain forest disturbance. —J. Appl. Ecol. 35: 454-457.

Pianka E.R. 1973: The structure of lizard communities. - Аnnu. Rev. Ecol. Syst. 4: 53-74.

PiANKA E.R. 1974: Niche overlap and diffuse competition. Proc. Natn. Acad. Sci. U.S.A. 71: 2141-2145.

PianKA E.R. 1976: Competition and niche theory. In May M. (ed.): Theoretical Ecology: Principles and Applications. Blackwell Scientific Publication, Oxford, pp. 114-141.

PiANKA E.R. 1978: Evolutionary Ecology. 2nd ed. Harper and Row, New York, 397 pp.

Price W.P., Denno R.F., Eubanks M.D., Finke D.L. \& Kaplan I. 2011: Insect Ecology: Behavior, Populations and Communities. Cambridge University Press, Cambridge, 828 pp.

Santoro R., Carboni M., Carranza M.L. \& Acosta A.T.R. 2012: Focal species diversity patterns can provide diagnostic information on plant invasions. - J. Nat. Conserv. 20: 85-91.

Schowalter T.D. 2011: Insect Ecology. An Ecosystem Approach. $3 r d$ ed. Elsevier Academic Press, London, 650 pp.

Ter BraAk C.J.F. \& ŠMILAuer P. 2002: CANOCO Reference Manual and CanoDraw for Windows User's Guide: Software for Canonical Community Ordination (version 4.5). Microcomputer Power, Ithaca, $500 \mathrm{pp}$.

Ulrich W. \& Gotelli N.J. 2007: Disentangling community patterns of nestedness and species co-occurrence. - Oikos 116: 2053-2061.

WhitTAKeR R.H. 1965: Dominance and diversity in land plant communities. - Science 147: 250-260.

WHITTAKER R.H. 1972: Evolution and measurement of species diversity. - Taxon 21: 213-251.

Winemiller K.O. \& PianKa E.R. 1990: Organization in natural assemblages of desert lizards and tropical fishes. - Ecol. Monogr. 60: 27-55.

Received March 23, 2016; revised and accepted June 28, 2016 Published online August 30, 2016 